\title{
"Optimizing Observations of Sea Ice Thickness and Snow Depth in the Arctic"
}

\author{
Jacqueline A. Richter-Menge \\ CRREL \\ 72 Lyme Road \\ Hanover, NH 03755 \\ phone: (603) 646-4266 fax: (603) 646-4534 \\ email: Jacqueline.A.Richter-Menge@usace.army.mil \\ Award Number: N0001412MP20150 \\ Dr. Sinead L. Farrell \\ University of Maryland, ESSIC \\ 5825 University Research Court, Suite 4001 \\ College Park, MD 20740 \\ phone: (301) 683-3332 fax: (301) 683-3330 \\ email: sineadf@umd.edu
}

Award Number: N000141210512

\section{LONG-TERM GOALS}

This work is motivated by the desire to improve the quality of airborne and satellite-based measurements of sea ice thickness and snow depth in the Arctic; to achieve a resolution that is adequate for monitoring decadal variability and to minimize the degree of uncertainty in predictive models.

\section{OBJECTIVES}

The specific objectives are:

- To carefully assess remotely-based observations of Arctic sea ice thickness and snow depth using a rare set of coordinated in situ, airborne, satellite and submarine measurements collected by US Army Corps of Engineering Cold Region Research and Engineering Laboratory (CRREL), Naval Research Laboratory (NRL) and National Aeronautics and Space Administration (NASA) in conjunction with the US Navy at the ICEX2011 sea ice field camp in March 2011 in the Alaskan Beaufort Sea;

- To leverage and integrate the measurements and results from this focused effort with data collected during related national and international activities (e.g. other NASA IceBridge sea ice missions, NRL under flights of CryoSat-2, European Space Agency (ESA) CryoVEx, submarine ice draft measurements, Alfred Wagner Institute (AWI) POLAR5) and historic ICESat records; 


\section{Report Documentation Page}

Form Approved

OMB No. 0704-0188

Public reporting burden for the collection of information is estimated to average 1 hour per response, including the time for reviewing instructions, searching existing data sources, gathering and maintaining the data needed, and completing and reviewing the collection of information. Send comments regarding this burden estimate or any other aspect of this collection of information,

including suggestions for reducing this burden, to Washington Headquarters Services, Directorate for Information Operations and Reports, 1215 Jefferson Davis Highway, Suite 1204, Arlington

VA 22202-4302. Respondents should be aware that notwithstanding any other provision of law, no person shall be subject to a penalty for failing to comply with a collection of information if it

does not display a currently valid OMB control number.

1. REPORT DATE

30 SEP 2014

4. TITLE AND SUBTITLE

Optimizing Observations of Sea Ice Thickness and Snow Depth in the Arctic

6. AUTHOR(S)

7. PERFORMING ORGANIZATION NAME(S) AND ADDRESS(ES)

U.S. Army Corps of Engineers, Cold Regions Research and Engineering Laboratory,72 Lyme Road,Hanover,NH,03755

9. SPONSORING/MONITORING AGENCY NAME(S) AND ADDRESS(ES)

\section{DATES COVERED}

00-00-2014 to 00-00-2014

5a. CONTRACT NUMBER

5b. GRANT NUMBER

5c. PROGRAM ELEMENT NUMBER

5d. PROJECT NUMBER

5e. TASK NUMBER

5f. WORK UNIT NUMBER

8. PERFORMING ORGANIZATION REPORT NUMBER

10. SPONSOR/MONITOR'S ACRONYM(S)

11. SPONSOR/MONITOR'S REPORT NUMBER(S)

12. DISTRIBUTION/AVAILABILITY STATEMENT

Approved for public release; distribution unlimited

13. SUPPLEMENTARY NOTES

14. ABSTRACT

15. SUBJECT TERMS

16. SECURITY CLASSIFICATION OF:

a. REPORT

unclassified b. ABSTRACT

unclassified c. THIS PAGE

unclassified
17. LIMITATION OF ABSTRACT

Same as

Report (SAR)
18. NUMBER 19a. NAME OF

OF PAGES RESPONSIBLE PERSON

8 
- To use these data to revise error estimates of remotely-derived snow depth and thickness data products from, for example, ICESat, IceBridge and CryoSat-2. These error estimates (a) are critical for understanding the variability and trends in the long-term time series of observations, (b) will help tie the various satellite and airborne records together, and (c) provide important input for predictive sea ice models.

\section{APPROACH}

The paramount transformative aspect of this work is the combined application of coincident ice thickness and snow depth measurements collected in March 2011 [Gardner et al., 2012]. The suite of measurements was strategically organized around a 9-km-long survey line that covered a wide range of ice types, including refrozen leads, deformed and undeformed first year ice and multiyear ice. The data set consists of coincident in situ field measurements of snow depth and ice thickness taken by the CRREL/NRL field team and airborne laser altimetry measurements of the surface elevation of the snow or ice/air interface, and radar altimetry measurements of the snow/ice interface, taken by NASA IceBridge and NRL airborne teams [Gardner et al., 2012]. This suite of data provides the full spectrum of spatial sampling resolution from satellite, to airborne, to ground-based, and will allow for a careful determination of snow depth on sea ice and sea ice thickness distributions. We have augmented the ICEX 2011 in situ measurement with additional airborne and in situ data gathered during the European Space Agency's CryoVex 2011 on thick, multi-year sea ice in the Lincoln Sea, to conduct an assessment of how airborne and satellite altimeter estimates are affected by deformed sea ice surfaces.

\section{Our culminating objective is to use results from the comparative assessment of these data to revise error estimates of remote snow depth and thickness data products, as a function of ice type. The} NASA airborne data consists of raw radar echograms from a snow radar, laser altimetry for surface topography and elevation, and visible digital photography for surface morphology. The primary in situ data comprise snow depth and sea ice thickness measurements. We initially concentrate on the issue of deriving accurate snow depth on sea ice, since snow depth uncertainty remains the largest source of error in deriving sea ice thickness from airborne/satellite altimeters. The outcome of the snow depth assessment can be directly applied to revise the airborne estimates of sea ice thickness. Advancements from this work will reduce the level of uncertainty in the observational records of sea ice trends and variability and, hence, increase our understanding of the complex interaction between the atmosphere, ice and ocean in the Arctic region. It will also help us to tie the ICESat, ICESat-2 and CryoSat-2 records together to provide a long-term time series, improving a critical resource for predictive sea ice models.

\section{WORK COMPLETED}

A comparative analysis of the data collected during the March 2011 field campaign in conjunction with ICEX2011 was the focus of Year 1, while in Year 2 the focus was an analysis of related NASA IceBridge (e.g. sea ice flights) data collected during other elements of the March and April 2011 campaign. Results of the work have been presented in two AGU Fall Meeting presentations in Year 1 and 2. In Year 3, a journal paper highlighting the analysis was completed and successfully submitted for publication. The list of work completed, following the proposed milestones and timeline (referenced to March 2012, project commencement):

- 12 months (Mar 2011): Sea ice field experiment at the ICEX 2011 Beaufort Sea ice camp. Acquisition of in situ, airborne and satellite data (Contributing parties: CRREL, NRL, NASA) 
- 1 month (Feb 2012): Publish EOS Brief [Gardner et al, 2012] describing coordinated field campaign, conducted near the ICEX2011 Beaufort Sea ice camp (CRREL, U Maryland, NRL)

+ 0 months (Mar 2012): Initial assessment of field data (CRREL, U Maryland, NRL)

+ 6 months (Sept 2012): Synthesis of in situ, IceBridge and NRL airborne data sets collected during ice camp with preliminary data analysis. Generate maps of ice thickness and snow depth for ice camp survey region. (CRREL, U Maryland, NRL)

+6 months (Sept 2012): Complete initial report on ice camp activities to include a full description of in situ data collected and success of field campaign. Details reported to ONR Arctic and Global

Prediction Program Office. (CRREL, U Maryland)

+ 9 months (Dec 2012): Attendance at AGU Fall Meeting to present results [Newman et al., 2012] and meet with international collaborators, laying the groundwork for Years 2 and 3 including data synthesis and coordination of future collaborative field programs (e.g. CryoVEx, AWI POLAR5). (U Maryland)

+16 months (July 2013): Conduct detailed comparative analysis of CryoSat-2 data with in situ and airborne data to assess the accuracy and precision of CryoSat-2 Arctic sea ice elevation, sea ice freeboard, and derived thickness. Initial work focused on simulation of the CryoSat-2 response in areas of level and ridged sea ice. (U Maryland, CRREL)

+ 18 months (Sept 2013): Continue analysis of combined NASA Icebridge Arctic 2011 campaign and provide report to ONR Arctic and Global Prediction Program Office. (U Maryland, CRREL)

+ 21 months (Dec 2013): Attendance at AGU Fall Meeting to present results [Farrell et al., 2013] and meet with international colleagues to continue collaboration on data synthesis and coordination of future field programs. (U Maryland)

+ 22 months (Jan 2014): Meet with colleagues from ESA and NRL to consider implications of analysis in the design of March 2014 field program (CRREL, U. Maryland, NRL, ESA)

+ 28 months (July 2014): Prepare and submit publication [Newman et al., 2014]. (UMD, CRREL)

+ 30 months (Sept 2014): Release ICEX2011 in situ snow and ice thickness data to NSIDC, for posting on NASA IceBridge website. (CRREL)

+ 30 months (Sept 2014): Invitation to attend NASA-sponsored snow thickness on sea ice workshop, presenting results of analysis (U Maryland, CRREL)

+ 30 months (Sept 2014): Complete analysis of combined NASA Icebridge and NRL Arctic 2011 data and provide report to ONR Arctic and Global Prediction Program Office. (CRREL, U Maryland)

\section{RESULTS}

A novel wavelet-based technique that operates on airborne snow radar echograms and provides automated snow depth retrievals has been developed and reported in Newman et al. [2014]. Snow depths are extracted on a waveform-by-waveform basis, without the need for spatial averaging. This approach results in approximately twice as many measurements as previously available (e.g. via the OIB IDCSI2 product at NSIDC) and provides robust, and repeatable, snow depth estimates over the sea ice pack. The technique is also generally applicable to airborne and spaceborne radar systems where interface detection of complex waveforms is required. 
Newman et al. [2014] applied the new wavelet-based snow depth retrieval technique to assess the uncertainty of snow depth estimates derived from the IceBridge airborne snow radar (SR), as a function of ice type. This was done by comparing SR snow depths to in situ (IS) measurements at the ICEX 2011 Arctic field site (Figure 1). Extending the results of Farrell et al. [2012], the analysis shows that the SR snow depth estimates are accurate over undeformed first year ice (UFY), with excellent $(1 \mathrm{~cm})$ agreement between the average SR and IS snow depths. Over deformed first year ice (DFY) ice and multiyear (MY) ice variable ice topography produces complex snow radar echograms that can result in ambiguous snow depth retrievals. For the case of angular DFY pressure ridges and rubble fields, the scattering surfaces are highly complex and this can result in an underestimation of snow depth by the SR. The hummocky surface of MY ice results in a higher potential for ice topography to be misinterpreted as a snow layer, even in the absence of snow on the sea ice, and will typically cause the SR to overestimate snow depth on MY ice. Where MY ice hummocks are buried by snow, the scattering geometry will likely result in bimodal snow depth distributions.

a
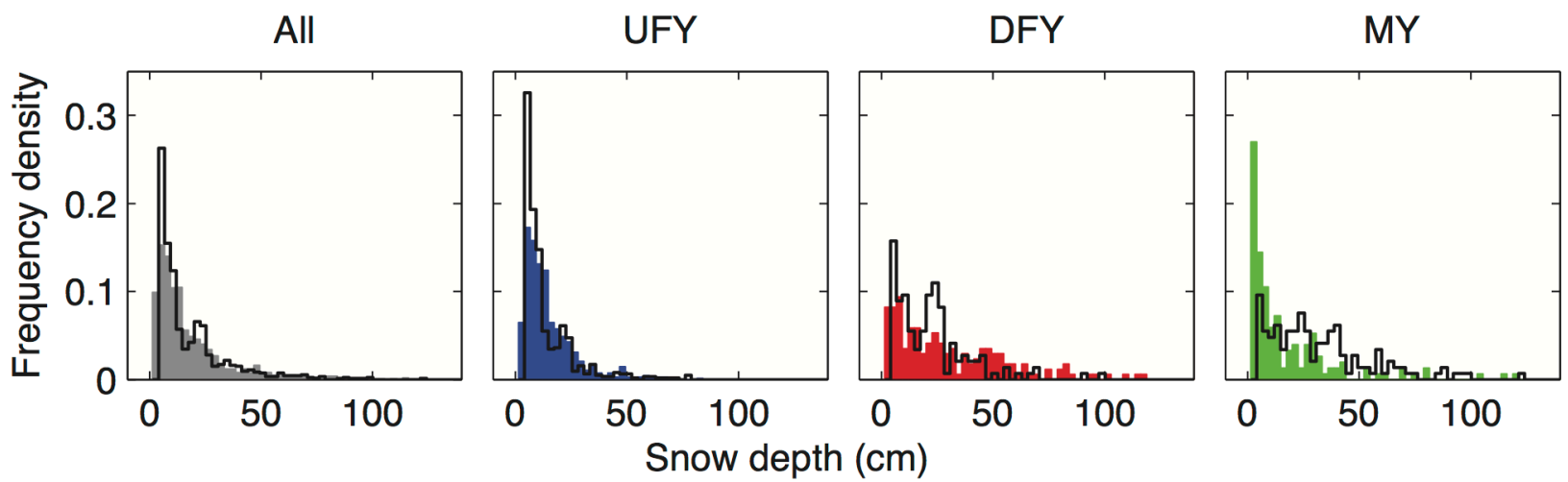

b

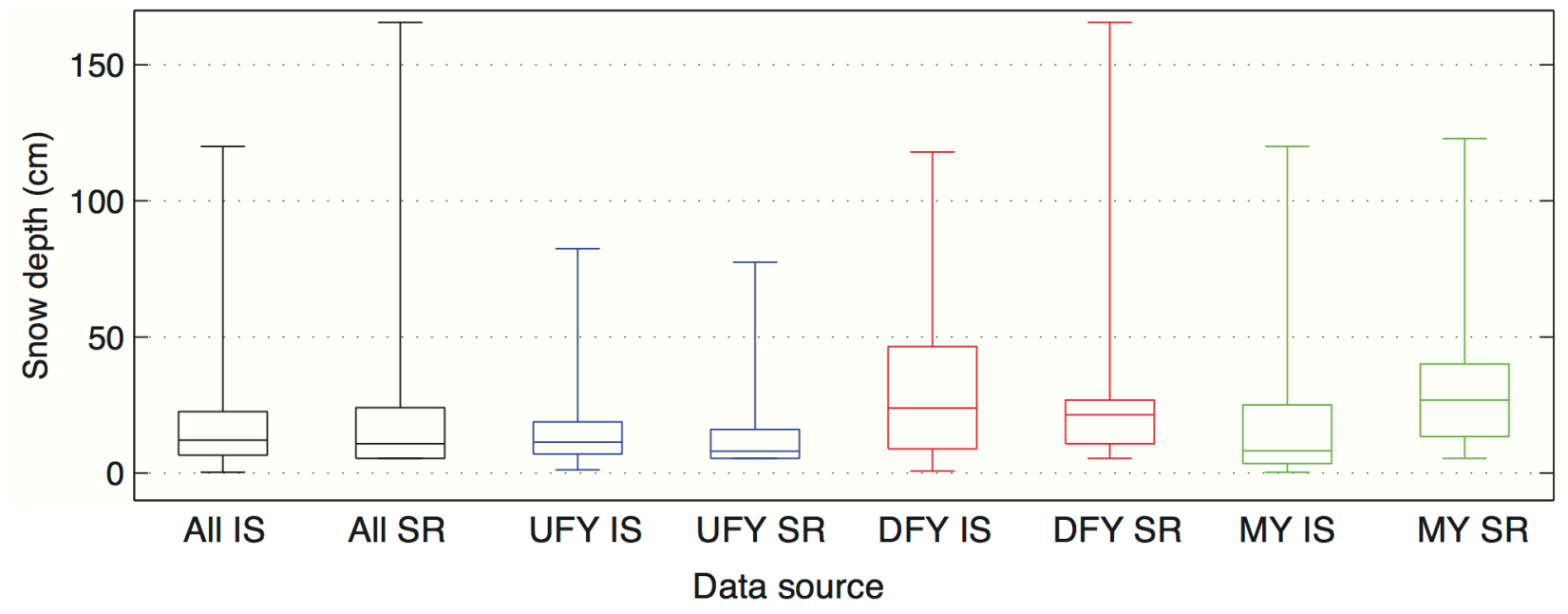

Figure 1. Histograms comparing coincident in situ (IS, color shading) and airborne snow-radarderived (SR, black line) snow depths for all ice types (All), undeformed first year (UFY) ice, deformed first year (DFY) ice, and mulityear (MY) ice along the ICEX 2011 survey line (bin width is $3 \mathrm{~cm}$ ) (b) Box and whisker plot (minimum, lower quartile, median, upper quartile, maximum) corresponding to the SR and IS snow depths shown in (a). (From Newman et al., 2014) 
This analysis also revealed that the first radar return above the noise floor in SR echograms may not necessarily come from the nadir point below the aircraft, but from the point on the surface at the minimum range to the aircraft (Figure 2, yellow line). This result suggests a limitation in the utility of a one-dimensional in situ survey line to assess the uncertainty of satellite and airborne snow radar measurements. Newman et al. [2014] recommend that future field surveys designed to test the accuracy of airborne snow or ice thickness estimates comprise a two-dimensional grid layout that captures both the along-track and across-track variability within the footprint of the remote sensing instruments. In fact, this gudiance was implemented in a March 2014 field campaign at multiple measurement locations in the western Arctic Ocean, supported by ESA, NRL, NASA, and ONR.

To mitigate the effect of ice deformation features on the retrieval of snow depths on regional and basin scales, and reduce/remove ambiguous snow depth estimates, a parameter has been developed to characterize ice topographic variability. This parameter is derived using airborne ATM laser altimeter elevation measurements and is available at the same (along-track) resolution as each SR snow depth estimate. It is used to discard ambiguous retrievals over deformed ice, thus providing details on seasonal snow accumulation on level ice. This approach is also useful for characterizing snow depth on large ice floes, which are preferentially sampled by spaceborne radar altimeters such as CryoSat- 2 .

Newman et al. [2014] compared the SR-derived snow depths for the 2011 and 2012 IceBridge campaigns across the western Arctic with the snow measurements described in Warren et al. [1999]. Snow depth results agreed in areas that continue to contain a high proportion of MY ice, such as north of Greenland and Ellesmere Island. Over much of the Beaufort Sea, Canada Basin and central Arctic we find that the SR-derived snow depths are up to 60\% of those reported in Warren et al. [1999]. These regions were previously dominated by MY ice during the Warren et al. [1999] measurement period (1954-91), but are now dominated by a seasonal ice cover.

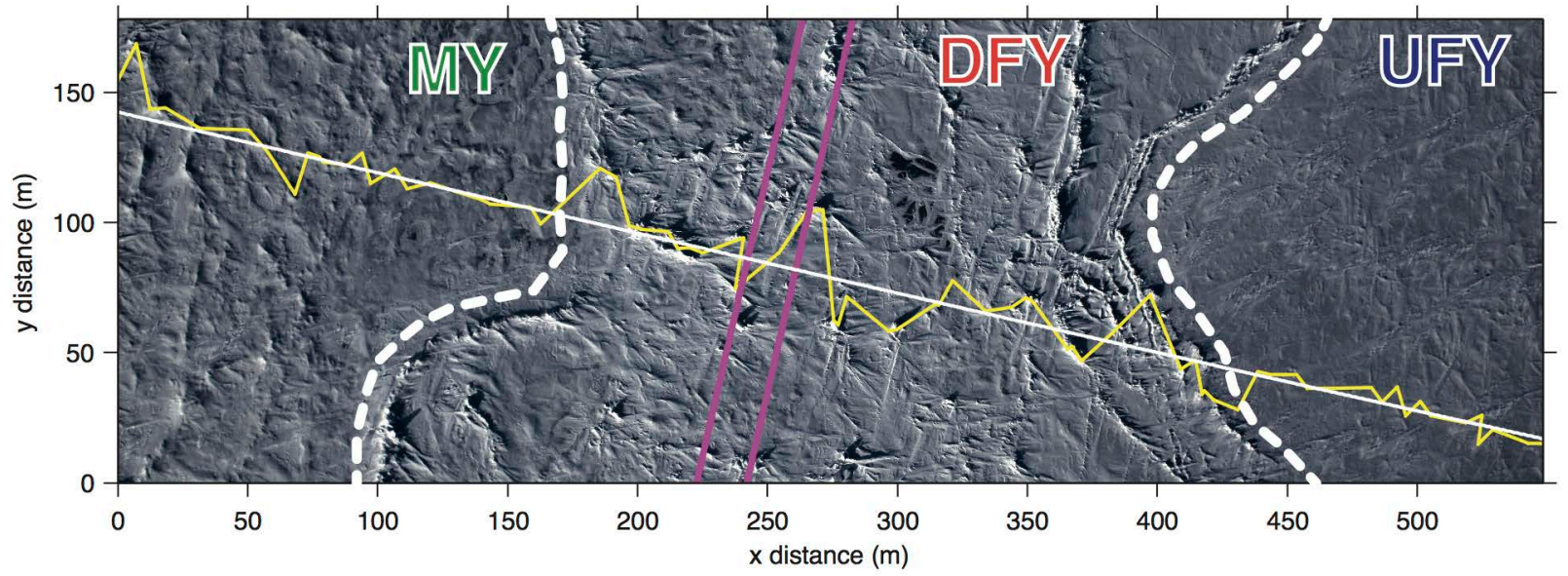

Figure 2. NASA IceBridge Digital Mapping System (DMS) image showing the characteristic sea ice surface morphology along the ICEX 2011 survey line. Regions of Multiyear ice (MY), deformed first-year ice (DFY) and undeformed first-year ice (UFY) are outlined (white dashed lines). Solid white line indicates the IceBridge flight path. Pink parallel lines show the along track dimensions of the IceBridge snow radar SAR-beam-limited footprint. Yellow line indicates the approximate location of the first radar return from the surface. (From Newman et al., 2014) 


\section{IMPACT/APPLICATIONS}

The revised error estimates of remotely-sensed snow depth and ice thickness observations generated by this investigation are critical for (1) understanding variability and trends in the long-term time series of NASA IceBridge observations, (2) tying the ICESat, ICESat-2 and CryoSat-2 records together, and (3) providing important input for predictive ice models. More specifically, the comparative study between the in situ data sets and coincident airborne and satellite data acquisitions will improve the understanding of new sensors. These include the University Kansas Center for Remote Sensing of Ice Sheets (CReSIS) snow radar, the NRL radar altimeter, and CryoSat-2's SIRAL radar altimeter. Recently, for example, the NASA IceBridge observations were used to validate sea ice thickness estimates from CryoSat-2 [Laxon et al., 2013].

Data collected at the ICEX 2011 ice camp include measurements of undeformed and deformed first year ice and multiyear ice. Consistent with the work of Farrell et al. (2012), the current investigation reveals differences, especially in accuracy, from several of the instruments as a function of ice type. Interpretation of radar data is particularly challenging over deformed first year ice and multiyear ice. This knowledge will be applied to aid in the analysis of the entire NASA IceBridge data set, including a re-evaluation of the level of uncertainty in snow depth and ice thickness estimates. Incorporating knowledge of these measurements and their accuracy into new algorithms will support improvements in regional sea ice models. The results will influence future sensor, and sensor suite, development and provide a metric for combining/contrasting future dataset collections. They will also affect the design of future field collection strategies, to improve the coupling of in situ, airborne and satellite observations, particularly the implementation of two dimensional in situ measurement grids.

\section{RELATED PROJECTS}

- NOAA: "Towards Operational Arctic Snow and Sea ice Thickness Products" is supported under the NOAA/NESDIS/STAR/SOCD Ocean Remote Sensing Program and is conducted in collbaoraiton with NASA IceBridge and CRREL. It continues to support the collection and reduction of a long-term time series of snow and sea ice thickness data in the Arctic Ocean. The goal is to continue the legacy of previous Arctic airborne campaigns conducted since 2002 to gather high-resolution altimetry over both seasonal and multiyear ice floes. These highresolution datasets are used as a calibration and validation tool to assess accuracy of satellite altimeter measurements (Envisat, ICESat and CryoSat-2) over sea ice.

- NASA IceBridge (www.nasa.gov/mission_pages/icebridge): The NASA IceBridge project is closely related to this ONR work, including an airborne survey over the 9-km ground line used to collect in situ snow and ice thickness data at the ICEX2011 field camp. The goal of IceBridge is to utilize a highly specialized fleet of instrumented research aircraft to characterize annual changes in the thickness of sea ice, glaciers, and ice sheets. These observations are critical for predicting the response of Earth's polar ice to climate change and sea-level rise. IceBridge will also bridge the gap in observations between NASA's ICESat satellite missions.

- NRL: " Determining the Impact of Sea Ice Thickness on the Arctic's Naturally Changing Environment (DISTANCE)". DISTANCE is providing direct support for a key element of our collaborative team, responsible for processing and analyzing the airborne data collected by NRL during the March 2011 field campaign. The objective of DISTANCE is to understand the changing Arctic environment, characterized by reduced ice volume and increased open water, 
using new techniques for deriving accurate multi-sensor snow and ice thickness information and coupled ice-ocean models to explore the new Arctic dynamics. The goal of DISTANCE is to provide the Navy with an improved forecast capability that accurately describes Arctic change, and new global fields of snow and ice thickness for data assimilation.

\section{REFERENCES}

Farrell, S. L., N. Kurtz, L. N. Connor, B. C. Elder, C. Leuschen, T. Markus, D. C. McAdoo, B. Panzer, J. Richter-Menge, and J. G. Sonntag (2012), A First Assessment of IceBridge Snow and Ice Thickness Data Over Arctic Sea Ice, IEEE Trans. Geosci. Rem. Sens., 50 (6), 2098 - 2111, doi:10.1109/TGRS.2011.2170843.

Gardner, J., J. Richter-Menge, S. Farrell and J. Brozena (2012), Coincident Multiscale Estimates of Arctic Sea Ice Thickness, EOS Trans. AGU, 93(6): 57-58.

Newman, T. S. L. Farrell, J. Richer-Menge, L.N. Connor, N.T. Kurtz, B.C. Elder, and D. McAdoo (2014) Assessment of radar-derived snow depth over Arctic sea ice, J. Geophys. Res., accepted for publication.

Warren, S.G. et al., (1999), Snow depth on Arctic sea ice, J. Clim., 12(6), pp.1814-1829.

\section{PUBLICATIONS}

Farrell, S. L., J. Richter-Menge, N. T. Kurtz, D. C. McAdoo, T. Newman, H. J. Zwally and J. Ruth (2013), A Decade of Arctic Sea Ice Thickness Change from Airborne and Satellite Altimetry (Invited), Abstract C11C-05, presented at 2013 Fall Meeting, AGU, San Francisco, Calif., 9-13 Dec. 2013. [non-refereed, conference abstract].

Gardner, J., J. Richter-Menge, S. Farrell and J. Brozena (2012), Coincident Multiscale Estimates of Arctic Sea Ice Thickness, EOS Trans. $A G U$, 93(6): 57-58. [published, refereed]

Kurtz, N., M. Studinger, S. Farrell, J. Paden, J. Richter-Menge, J. Sonntag, and J. Yungel (2013), IceBridge Airborne Survey Data Support Arctic Sea Ice Predictions, EOS Trans. AGU, 94(4), 41, doi: 10.1002/2013EO040001. [published, refereed]

Kurtz, N., S. L. Farrell, M. Studinger, N. Galin, J. Harbeck, R. Lindsay, V. Onana, B. Panzer, and J. Sonntag (2013), Sea ice thickness, freeboard, and snow depth products from Operation IceBridge airborne data, The Cryosphere, 7, 1035-1056, doi:10.5194/tc-7-1035-2013. [published, refereed]

Laxon, S.W., Giles, K. A., Ridout, A. L., Wingham, D. J., Willatt, R., Cullen, R., Kwok, R., Schweiger, A., Zhang, J., Haas, C., Hendricks, S., Krishfield, R., Kurtz, N., Farrell, S. L., Davidson, M. (2013), CryoSat Estimates of Arctic Sea Ice Volume, Geophys. Res. Lett., 40, doi:10.1002/grl.50193. [published, refereed]

Newman, T., S. L. Farrell, J. Richter-Menge, L. N. Connor, N. T. Kurtz, B. C. Elder (2012), An assessment of IceBridge airborne data quality over Arctic sea ice via comparison with in situ measurements gathered in the Beaufort Sea, Abstract C11B-04, presented at 2012 Fall Meeting, AGU, San Francisco, Calif., 3-7 Dec. 2012. [non-refereed, conference abstract]

Newman, T. S. L. Farrell, J. Richer-Menge, L.N. Connor, N.T. Kurtz, B.C. Elder, and D. McAdoo (2014) Assessment of radar-derived snow depth over Arctic sea ice, J. Geophys. Res. [accepted for publication, referred] 
Onana, V. D. P., N. T. Kurtz, S. Farrell, L. S. Koenig, M. Studinger, and J. P. Harbeck (2013), A Sea Ice Lead Detection Algorithm for use with High Resolution Airborne Visible Imagery, IEEE Trans. Geosci. Rem. Sens., 51(1), 38-56, doi: 10.1109/TGRS.2012.2202666. [published, refereed]

Richter-Menge, J., and S. L. Farrell (2013), Arctic Sea Ice Conditions in Spring 2009 - 2013 Prior to Melt, Geophys. Res. Lett., 40, 5888-5893, doi: 10.1002/2013GL058011. [published, refereed]

Tsamados, M., D. Feltham, D. Schroeder, D. Flocco, S. Farrell, N. Kurtz, S. Laxon, and S. Bacon (2014), Impact of atmospheric and oceanic form drag on simulations of Arctic sea ice, J. Phys. Oceanog, JPO-D-13-0215, doi: 10.1175/JPO-D-13-0215.1. [published, refereed]

Webster, M. A., I. G. Rigor, S. V. Nghiem, N. T. Kurtz, S. L. Farrell, D. K. Perovich, and M. Sturm (2014), Interdecadal Changes in Snow Depth on Arctic Sea Ice, J. Geophys. Res., 119, 53955406, doi:10.1002/2014JC009985. [published, refereed] 